\title{
Evaluation of DMFT and CPITN Indices among Users of Various Drugs
}

\author{
Khadijeh Abdal ${ }^{1}$, Reza Vilizadeh², Aref Nazari³ ${ }^{3}$, Mohammad Reza Hafezi Ahmadi, Mohammad Ali Rozgar ${ }^{5}$
}

${ }^{1}$ Assistant professor, Department of Oral and Maxillofacial Pathology, Faculty of Dentistry, Ilam University of Medical Sciences, Ilam, Iran. ${ }^{2}$ Associate professor, Department of Psychiatry, Faculty of Medicine, Ilam University of Medical Sciences, Ilam, Iran. ${ }^{3}$ Student of dentistry, Department of Dentistry, Faculty of Dentistry, Ilam University of Medical Sciences, Ilam, Iran. ${ }^{4}$ Associate professor, Department of Pathology, Faculty of Medicine, Ilam University of Medical Sciences, Ilam, Iran and Associate professor, Biotechnology and Medicinal Plants Research Center, Ilam University of Medical Sciences, Ilam, Iran. ${ }^{5}$ Associate professor, Department of Periodentistry, Faculty of Dentistry, Ilam University of Medical Sciences, Ilam, Iran.

\section{ABSTRACT}

\section{BACKGROUND}

Addiction, in addition to social and economic problems, can cause serious oral health complications and impose huge costs of treatment and elimination of oral health problems among addicts. The present study was conducted to investigate DMFT and CPITN indices among drug users in Ilam's addiction treatment center.

\section{METHODS}

This is a cross-sectional study, conducted in Ilam's addiction treatment centers and all patients who visited the centers for drug rehabilitation for one month were closely examined and studied. Clinical examinations were performed by the dentist in order to evaluate DMFT and CPITN indices. The collected data was analysed by SPSS version 18. ANOVA and t-student were used to examine the individual information and oral indices.

\section{RESULTS}

Most of the patients were aged between 30 to 40 years and their mean age was 42.16 \pm 5.6 ; the youngest subject was 20 and the eldest was 77 years old, who were addicted to marijuana and opium. 197 (97.5\%) male and 5 (2.5\%) female subjects were studied. 130 patients (64.5\%) were addicted to opium, $26(12.8 \%)$ to heroine, $20(9.9 \%), 11(5.4 \%)$ to crack $15(7.4 \%)$ were addicted to marijuana. 147 (73\%) of addicts had dyspepsia and 98 (48.5\%) had severe dental sensitivity. Temporomandibular joint disorders were observed in 84 (42\%) patients; severe gingival bleeding was observed in 42 cases. The mean DMFT index turned out to be 15.8 in this study. Drug users in this study had an inappropriate oral and dental health status.

\section{CONCLUSIONS}

Proper oral health and preventive dental care interventions are strongly recommended in treatment centers.

\section{KEY WORDS}

DMFT, CPITN, Addiction, Oral Health, Drugs

\author{
Corresponding Author: \\ Mohammad Ali Rozgar, \\ Department of Periodentistry, \\ Faculty of Dentistry, \\ Ilam University of Medical Sciences, \\ Ilam, Iran. \\ E-mail: dr.faribaabdal@yahoo.com
}

DOI: $10.14260 / \mathrm{jemds} / 2019 / 631$

Financial or Other Competing Interests: Dr. Rozgar reports grant from Ilam University of Medical Sciences, Outside the Submitted Work.

How to Cite This Article:

Abdal K, Vilizadeh $R$, Nazari $A$, et al. Evaluation of DMFT and CPITN indices among users of various drugs. J. Evolution Med. Dent. Sci. 2019;8(38):2907-2910, DOI: $10.14260 /$ jemds/2019/631

Submission 13-07-2019,

Peer Review 10-09-2019,

Acceptance 16-09-2019,

Published 23-09-2019. 


\section{BACKGROUND}

Addiction is a chronic disease the close analysis of which is of paramount importance due to oral and dental health in addition to numerous social and economic problems. Undoubtedly, the type of drug used and its mode of use affect the quality and extent of oral health injuries.(1) The viewpoints of addicted people towards the principles of oral hygiene, preservation of beauty and efficiency of teeth are not very positive; thus, they cannot be expected to observe health principles; this same approach has provided the basis for generating an unhealthy environment in the mouth and the occurrence of various types of oral and dental disorders. (2) Types of drugs and tobacco are used by eating, sucking, injecting and inhalation, and due to the close proximity to oral and dental tissues, gradually the teeth and their retaining tissues are damaged.(3) Unfortunately, the destructive effects of these materials on the teeth and tissues of the mouth are so rapid and widespread that addicted individuals are sometimes identified by paying attention to their oral health and dental tissues. Substances that affect oral hygiene include cocaine, crack, crystal, amphetamines, alcohol, opium, marijuana and tobacco.(4) Cocaine is a strong acidic stimulant for teeth and causes decomposition of enamel. Inhaling cocaine powder can damage the palate and create a hole between the nose and mouth. Rubbing cocaine powder into the gum causes oral ulcers.(5) Using cocaine causes muscle spasms in the jaw and mouth, the ultimate result of which is bruxism. Since crack is smoked to be used, it has a direct impact on teeth.(6) Using crustal causes meth mouth because the drug quickly eliminates the teeth and affects the tissue of the gums by damaging blood vessels; crystal causes a severe reduction in saliva, and individuals addicted to this substance suffer from severe stroke.(7) Reducing the amount of saliva and the high tendency of these people to consume sweets increases the rate of tooth decay. Amphetamines, known as ecstasy, MDMA and mole, are known to cause severe oral and tooth bleeding in consumers. ${ }^{(8,9)}$ Alcohol is an acidic substance that is made from fermentation of sugars that quickly decay teeth. Colourful alcoholic beverages such as wine leave stain on the crown of the teeth and make them unpleasant to look at. (5,7) Opium and opioids, such as heroin, cause severe damage to the crown and root of the tooth. Also, individuals addicted to these substances have a high inclination to use sugary substances, thus causing high incidence of bruxism.(10) When heroin is inhaled, the risk of developing fungal and viral infections increases in the mouth. Marijuana can cause cancer in the mouth, $(3,8)$ by causing dryness in the mouth, this drug eliminates tooth enamel and causes tooth decay. Smoking and chewing tobacco increase the risk of oral cancer. (11) Tobacco use can cause severe dry mouth, bad breath, and colour changes in the tissues of the mouth and gum disease. (3) Regardless of the negative consequences of drug use, unfortunately, according to statistics, there are more than 1 million and 700 thousand people with an average age of 32 years in Iran.(4) Research shows that the most commonly used drug used in Iran belongs to the opioid group, including opium, sap, heroin and cotyledon.(7) Since treatment and rehabilitation of addicts imposes huge costs on community and considering the importance and seriousness of oral health problems, it is necessary to develop a proper care plan and approach. The oral health of addicts is considered to be a dental service that should be included in the comprehensive health program of the country, which will reduce dental complications and facilitate their return to the community. The present study was conducted to evaluate the DMFT (Decimal-missing-filledteeth index) and CPITN (Community-Periodontal-Index-ofTreatment-Needs) indices among drug users in Ilam's addiction treatment center in order to improve the oral and dental health of these people and develop educational programs to prevent the use of narcotic drugs for other people in society, including students and university students, by collecting information.

\section{METHODS}

This cross-sectional study was conducted in Ilam's addiction centers and all people who visited the centers for drug rehabilitation for one month were closely examined and studied (202 subjects). Questionnaires were filled by interviewing the subject about sex, age, history of addiction, type of drug abuse, occupation, educational level, place of residence and marital status. After the interview, the clinical examinations were performed by the dentist to assess the DMFT and CPITN indices. Before the oral examination, one toothbrush and toothpaste were given to each subject. After brushing, patients were examined on a regular chair using a flashlight, a WHO probe; a Williams graded catheter and a disposable mirror. The DMFT index is a formula that determines the number of rotten, dropped, and filled teeth the checklist of which is completed for each individual. The data was analysed by SPSS-18. ANOVA and t-student was used to examine the individual information and oral indicators. The significance level was considered less than 0.05 .

The present project was approved at the Ethics Committee of Ilam University of Medical Sciences. Prior to the commencement of the project, the written consent of each participant was obtained, and he/she was ensured about the confidentiality of information.

\section{RESULTS}

The present study was conducted on 202 drug addicts admitting to the addiction treatment centers in Ilam. Most of the patients were between $30-40$ years and the mean age was $42.16 \pm 5.6$ The youngest was 20 and the eldest was 77 years old, and they were addicted to weed and opium. 197 (97.5\%) patients were male and $5(2.5 \%)$ were female (Table 1$)$. $71.5 \%$ had no history of referring to the dentist, and $57 \%$ did not have toothbrushes. The highest smoking rate was 40 cigarettes per day, observed among opium users. 147 (73\%) addicts had dyspepsia problem and 98 (48.5\%) had severe dental sensitivity (Table 2). The highest rate of dryness and dental sensitivity were observed among heroin users. Temporomandibular-joint disorders were seen in 84 patients (42\%), mostly among crystal users. Aphthous stomatitis was observed in 20 cases, herpetic in 35 cases, candida in 24 cases, leukoplakia in 6 cases, and oral mucosal pigmentation in 86 cases. 38 patients had complete prosthesis, 15 patients 
had partial prosthesis and 21 had fixed prosthesis. Based on the CPITN index, 4 cases had healthy gums, 55 cases had gingival bleeding (Code 1), 93 had dental masses (Code 2), 64 had $4 \mathrm{~mm}$ probe depths (Code 3 ), and 43 had more than 4 $\mathrm{mm}$ probe depths (Code 4); severe gingival bleeding was observed in 42 cases. The mean DMFT index in this study was $15.8,0.9 \%$ of the teeth were restored in each subject, $3.8 \%$ of teeth were rotten and $5.5 \%$ of teeth were lost.

\begin{tabular}{|c|c|c|c|c|c|c|c|}
\hline \multicolumn{2}{|c|}{ Variables } & No. & $\%$ & $\begin{array}{c}\text { Mean } \pm \text { SD } \\
\text { DMFT }\end{array}$ & $\begin{array}{c}\text { p- } \\
\text { Value } \\
\text { DMFT }\end{array}$ & $\begin{array}{c}\text { Mean } \pm \text { SD } \\
\text { CPITN }\end{array}$ & $\begin{array}{c}\text { p- } \\
\text { Value }\end{array}$ \\
\hline \multirow{5}{*}{ Age group } & $20-30$ & 38 & $18.8 \%$ & $12 / 5+4 / 6$ & \multirow{5}{*}{0.02} & $22 / 5+3 / 6$ & \multirow{5}{*}{0.004} \\
\hline & $31-40$ & 65 & $32.2 \%$ & $13 / 7+5 / 6$ & & $24 / 5+4 / 2$ & \\
\hline & $41-50$ & 52 & $25.7 \%$ & $17 / 5+3 / 6$ & & $25 / 5+2 / 6$ & \\
\hline & $51-60$ & 34 & $16.8 \%$ & $21 / 5+4 / 6$ & & $27 / 5+4 / 3$ & \\
\hline & $61-70$ & 13 & $6.5 \%$ & $27 / 5+2 / 6$ & & $28 / 5+4 / 6$ & \\
\hline \multirow{2}{*}{ Gender } & Male & 197 & $97.5 \%$ & $17 / 5+2 / 6$ & \multirow[b]{2}{*}{0.32} & $18 / 5+3 / 6$ & \multirow[b]{2}{*}{0.021} \\
\hline & Female & 5 & $2.5 \%$ & $21 / 8+4 / 6$ & & $23 / 7+4 / 2$ & \\
\hline \multirow{2}{*}{ Marriage } & Single & 48 & $23.7 \%$ & $17 / 5+3 / 6$ & \multirow{2}{*}{0.06} & $22 / 5+4 / 2$ & \multirow[b]{2}{*}{0.0} \\
\hline & Married & 154 & $76.3 \%$ & $16 / 5+4 / 6$ & & $28 / 5+3 / 6$ & \\
\hline \multirow{3}{*}{ Job } & Employee & 25 & $12.3 \%$ & $16 / 5+4 / 6$ & \multirow{3}{*}{0.07} & $25 / 5+2 / 6$ & \multirow{3}{*}{0.045} \\
\hline & Free job & 134 & $66.4 \%$ & $17 / 7+3 / 5$ & & $30 / 7+3 / 5$ & \\
\hline & Unemployed & 43 & $21.3 \%$ & $19 / 3+4 / 7$ & & $33 / 9+4 / 6$ & \\
\hline \multirow{5}{*}{ Education } & Illiterate & 7 & $3.5 \%$ & $19 / 5+5 / 6$ & \multirow{5}{*}{0.09} & $22 / 2+3 / 6$ & \multirow{5}{*}{0.034} \\
\hline & Cycle & 128 & $63.4 \%$ & $19 / 4+6 / 6$ & & $28 / 5+4 / 2$ & \\
\hline & Diploma & 47 & $23.3 \%$ & $16 / 5+4 / 3$ & & $30 / 7+2 / 4$ & \\
\hline & $\begin{array}{c}\text { Licentiate } \\
\text { degree }\end{array}$ & 15 & $7.4 \%$ & $17 / 7+6 / 5$ & & $33 / 6+4 / 1$ & \\
\hline & And more & 5 & $2.45 \%$ & $16 / 6+8 / 6$ & & $36 / 5+3 / 6$ & \\
\hline
\end{tabular}

\begin{tabular}{|c|c|c|c|}
\hline \multicolumn{2}{|c|}{ Variables } & Number & Percentage \\
\hline \multirow{3}{*}{ Dental condition } & Full dentures & 38 & $18.9 \%$ \\
\cline { 2 - 4 } & Partial denture & 15 & $7.6 \%$ \\
\cline { 2 - 4 } & Fixed prosthesis & 21 & $10.25 \%$ \\
\hline \multirow{2}{*}{ Oral pigmentation } & Have & 86 & $42.6 \%$ \\
\cline { 2 - 4 } & No have & 116 & $57.4 \%$ \\
\hline \multirow{2}{*}{ Xerostomia } & Have & 147 & $23.7 \%$ \\
\cline { 2 - 4 } & No have & 55 & $76.3 \%$ \\
\hline \multirow{2}{*}{ Dental sensitivity } & Have & 98 & $48.5 \%$ \\
\cline { 2 - 4 } & No have & 104 & $51.5 \%$ \\
\hline \multirow{3}{*}{ Oral ulcer } & Aphthous ulcers & 20 & $9.9 \%$ \\
\cline { 2 - 4 } & Herpetic ulcers & 35 & $17.3 \%$ \\
\cline { 2 - 4 } & Candidiasis & 24 & $11.8 \%$ \\
\hline
\end{tabular}

Table 2. Distribution of Addicts according to the Dental Condition, Oral Ulcers, Leukoplakia, Candida, Xerostomia and TMD

\section{DISCUSSION}

Given that few studies have been conducted on the oral and dental problems of drug users, the present study can explain some of the oral and dental problems and its effective factors, hoping to establish interventions to improve the oral health of addicts on the level of community. According to the present study, the mean age of the population was $6.5 \pm 16.42$ years, with an age range of 30-40 years; the youngest and oldest subjects were 20 and 77 years old. According to the results of O'sullivan study in Ireland, 59\% of the subjects under study were under 40 years of age and that the age range of the subjects was 18-73 years, which is similar to the results of the current study.(9) A study conducted in Aligudarz and Ardebil showed that the mean age of addicts was 34.5 and 36.3 years, indicating that most addicts were between the ages of 30 and 40 , thus creating the chance of returning to society. $(10,11)$ Unfortunately, the oral complications of drug abuse affect the individual and social functions of the individual, isolating the addict due to unpleasant appearance; consequently, the severity of addiction increases and the likelihood of rehabilitation is reduced; therefore, paying more attention to eliminating the oral problems of these people becomes more and more important and the necessity of rehabilitation becomes increasingly significant. In regard with education, $63 \%$ of subjects had completed secondary education; additionally, it was observed that addiction is less common among educated students.

The mean DMFT index was $15.8 \%$ in this study, a rate which was $14.4 \%$ in O'sullivan's and $16 \%$ in Akbari's study. ${ }^{(9,12)}$ The prevalence of dry mouth was $73 \%$ in this study, a rate which turned out to be $50 \%$ in Ayramloo's research.(13) Dry mouth is an important factor in increasing the incidence of dental caries, periodontal problems and TMD disorders. The main cause of dry mouth remains unclear due to the use of drugs, and drugs, especially methamphetamine compounds, appear to reduce the flow of saliva by vasoconstriction. The prevalence of TMD was $42 \%$ in this study, which was similar to the results of Almus and Akbari studies that reported a prevalence of $41 \%$ and $36.5 \%$ for TMD.(12,14) The results of Shetty's studies showed a prevalence of $22.3 \%$ for TMD.(15) These findings suggest that drugs are likely to increase oral pigmentation habits. Dental pigmentation and oral mucosa were observed in $43 \%$ of cases, which with a rate of $30.8 \%$, was reported as the most common complication in Shirazi's study.(16) The results of Akbari's studies showed the rate of oral pigmentation in addicts to be $34.5 \%$, which is consistent with the results of the present study.(12) The prevalence of oral ulcers and herpes was $25 \%$ among subjects, which turned out to be similar to that of the 0'sullivan's study, which reported a rate of $20 \%$ for the incidence of oral ulcers. ${ }^{(9)}$ In the present study, $3 \%$ of subjects had leukoplakia, which was quite similar to the results of the Akbari study, with a rate of $4 \%$.(12) Sujutha and Patil reported a $14 \%$ and $8.2 \%$ incidence of leukoplakia, respectively.(17,18) $57 \%$ of the addicts participating in the present research never brushed; however, $44.2 \%$ of subjects either didn't brush or brushed quite infrequently in Ghane's study.(19) In a study conducted in the Netherlands, $48 \%$ of subjects with a history of drug abuse were brushing at least once a day; in Morio's study, roughly $40 \%$ of subjects brushed at least once daily.(20,21) In this study, $28.5 \%$ of the patients had referred to the dentist over the past year and $83 \%$ of them had gone to health centers due to tooth decay. In Ghane's study, $31.5 \%$ of drug addicts had referred to dental centers during the last 12 months, which is consistent with the results of the present study.(19) In Schekarchizadeh's study, more than half of the subjects (57\%) had gone to a dentist in the past year.(22) In Mckenna and Laslett's studies, $22.4 \%$ and $40 \%$ of drug addicts had referred to dentistry during the past year. $(23,24)$

\section{CONCLUSIONS}

According to the findings of the present study, besides the destructive effects of narcotic drugs on oral tissues, lack of oral hygiene, inappropriate nutrition, increased sugar content and lack of referral to the dentist are some of the most important causes of oral and dental problems among individuals with drug abuse history. Considering the results of the present study, it seems that attention to oral and dental health of addicted people and encouraging them to undergo addiction rehabilitation is of special importance. The 
development of comprehensive programs for oral health promotion of such people seems essential. Therefore, it is recommended to provide proper training of oral health and implement preventive dental interventions in addiction treatment centers

\section{ACKNOWLEDGEMENT}

This article is based on a research project approved by the Ethics Committee of Ilam University of Medical Sciences. I am grateful to Ilam University of Medical Sciences for the financial support during the conduct of this study.

\section{REFERENCES}

[1] Tavakoli M, Mohammadi L, Yarmohammadi M, et al. Status and trend of substance abuse and dependence among Iranian Women. J Rehabil 2014;14(5):30-7.

[2] Panahi J, Havasian MR, Roozegar MA. Knowledge of physical education teachers' toward tooth avulsion in Tehran, Iran. J Oral Health Oral Epidemiol 2014;3(2):6671.

[3] Roozegar MA, Havasian MR, Panahi J, et al. The prevalence of the localized aggressive periodontitis among students at 14-16 years in Ilam, Iran. Der Pharmacia Lettre 2014;6(6):62-4.

[4] Gupta T, Shah N, Mathur VP, et al. Oral health status of a group of illicit drug users in Delhi, India. Community Dent Health 2012;29(1):49-54.

[5] Ma H, Shi XC, Hu DY, et al. The poor oral health status of former heroin users treated with methadone in a Chinese city. Med Sci Monit 2012;18(4):PH51-5.

[6] Akbari M, Faghani M, Kazemian A, et al. Evaluation of oral health status and dental need assessment in narcotic drug abusers. J Mash Dent Sch 2015;39(3):191-200.

[7] Rafee H. The latest statistics of Iranian drug abusers published. 2013. Accessed October 01, 2013. 3. http://www.farsnews.com/newstext.php?nn=86110103 14.

[8] Heymann H, Swift E, Ritter A. Sturdevant's Art and Science of Operative Dentistry. $6^{\text {th }}$ edn. St. Louis: Elsevier Publication 2013.

[9] O'Sullivan EM. Dental health of Irish alcohol/drug abuse treatment centre residents. Community Dent Health 2012;29(4):263-7.

[10] Foroughi S. Aligoudarz township self - introduced addicts, characteristics. Yafteh 2004;5(1):57-61.

[11] Amani F, Sadeghie S, Salamati P. Characterization of narcotic drug abusers visited in Ardebil self-referred centers. Payesh 1994;4(1):55-9.
[12] Akbari M, Afshari R, Sharif M, et al. Evaluation of the effect of diacetyl morphine on salivary factors and their changes after methadone therapy. J Contemp Dent Pract 2014;15(6):730-4.

[13] Ayramloo B, Fathieh A, Kamel H. The effect of the use of psychedelic substances on incidence and intensity of periodontitis and dental caries. J Dent Sch Shahid Beheshti Univ Med Sci 2001;19(1):12-6.

[14] Almas K, Al Wazzan K, Al Hussain I, et al Temporomandibular joint status, occlusal attrition, cervical erosion and facial pain among substance abusers. Odontostomatol Trop 2007;30(117):27-33.

[15] Shetty V, Mooney LJ, Zigler CM, et al. The relationship between methamphetamine use and increased dental disease. J Am Dent Assoc 2010;141(3):307-18.

[16] Shirzaei M. Oral changes associated with tobacco and opioids consumption in patients referred to Zahedan Dental School. J Qazvin Univ Med Sci 2011;15(3):62-8.

[17] Sujatha D, Hebbar PB, Pai A. Prevalence and correlation of oral lesions among tobacco smokers, tobacco chewers, areca nut and alcohol users. Asian Pac J Cancer Prev 2012;13(4):1633-7.

[18] Patil PB, Bathi R, Chaudhari S. Prevalence of oral mucosal lesions in dental patients with tobacco smoking, chewing and mixed habits: a cross-sectional study in South India. J Family Community Med 2013;20(2):130-5.

[19] Ghane M, Pourhashemi SJ, Jafari A, et al. Oral health behavior of in-treatment femaledrug addicts in Tehran Mehrdad. Journal of Dental Medicine-Tehran University of Medical Sciences 2016;29(1):60-9.

[20] Molendijk B, Horst GT, Kasbergen M, et al. Dental health in Dutch drug addicts. Community Dent Oral Epidemiol 1996;24(2):117-9.

[21] Morio KA, Marshall TA, Qian F, et al. Comparing diet, oral hygiene and caries status of adult methamphetamine users and nonusers: a pilot study. J Am Dent Assoc 2008;139(2):171-6.

[22] Shekarchizadeh H, Ekhtiari H, Khami MR, et al. Patterns of pre-treatment drug abuse, drug treatment history and characteristics of addicts in methadone maintenance treatment in Iran. Harm Reduct J 2012;9:18.

[23] McKenna G, Madden J, Manton S, et al. Survey of oral health behaviours of patients receiving methadone therapy at a drug rehabilitation centre. J Theor Pract Dent Pub Health 2013;1(3):6-13.

[24] Laslett AM, Dietze P, Dwyer R. The oral health of street recruited injecting drug users prevalence and correlates of problems. Addiction 2008;103(11):1821-5. 